\title{
Interleukin-13, but Not Indomethacin, Increases Cysteinyl-Leukotriene Synthesis in Human Lung Macrophages
}

\author{
Sarah E. Jackson, John W. Holloway, Jane A. Warner, and Anthony P. Sampson \\ Infection, Inflammation and Immunity Division, University of Southampton School of Medicine, Southampton SO16 6YD, UK \\ Correspondence should be addressed to Anthony P. Sampson, aps@soton.ac.uk
}

Received 30 June 2011; Accepted 26 August 2011

Academic Editor: Luis M. Teran

Copyright () 2012 Sarah E. Jackson et al. This is an open access article distributed under the Creative Commons Attribution License, which permits unrestricted use, distribution, and reproduction in any medium, provided the original work is properly cited.

Aspirin-exacerbated respiratory disease (AERD) is associated with constitutively elevated synthesis of bronchoconstrictor cysteinyl-leukotrienes, associated with increased expression of leukotriene (LT) $\mathrm{C}_{4}$ synthase and Th2 cytokines and airway eosinophilia. We examined whether interleukin-13 can increase LTC $_{4}$ synthase gene transcription and cysteinyl-leukotriene synthesis in macrophages isolated from resected human lung tissue and whether an NSAID (indomethacin) can trigger further cysteinylleukotriene synthesis in these cells. Overnight culture of human lung macrophages with IL-13 (10 ng/mL) increased spontaneous and ionophore-stimulated production of cysteinyl-leukotrienes by $42 \%(P=0.02)$ and $52 \%(P=0.005)$, respectively, as quantified by enzyme immunoassays, but PCR gene transcription assays did not demonstrate an effect on LTC4S mRNA. The addition of indomethacin $(100 \mu \mathrm{M})$ did not modulate cysteinyl-leukotriene production in either IL-13-treated or untreated macrophages. We conclude that while IL-13 enhances cysteinyl-leukotriene synthesis in human lung macrophages, it does not replicate the enhanced $\mathrm{LTC}_{4}$ synthase expression observed in the AERD lung nor confer sensitivity to NSAIDs.

\section{Introduction}

Aspirin-exacerbated respiratory disease (AERD) is a syndrome in which chronic asthma is accompanied by nonallergic hypersensitivity to nonsteroidal anti-inflammatory drugs (NSAIDs), leading to acute bronchoconstriction and exacerbation of other lower and upper airway symptoms $[1,2]$. The ability of classical NSAIDs to inhibit prostaglandin synthesis by cyclooxygenase (COX) isozymes, particularly COX-1, is implicated in these acute exacerbations [3], but it is not known how they activate mast cells, eosinophils, macrophages, epithelium, and other cells to release a range of inflammatory mediators in susceptible subjects.

Prominent among these mediators are the cysteinylleukotrienes (cys-LTs), which are potent bronchoconstrictor lipids synthesised by the 5 -lipoxygenase $(5-\mathrm{LO}) / \mathrm{LTC}_{4}$ synthase pathway [4]. Compared to NSAID-tolerant asthmatics, AERD patients have chronically elevated production of cysLTs, as demonstrated in bronchoalveolar lavage (BAL) fluid, induced sputum, exhaled breath condensate, and urine [2]. Together with the clinical efficacy of antileukotriene drugs
[5], this suggests a key role of cys-LTs in chronic AERD, even when NSAIDs are entirely avoided. Exposure to NSAIDs is postulated to shunt the shared substrate arachidonic acid from the prostaglandin (cyclooxygenase) pathway to the leukotriene (5-lipoxygenase) pathway, or to reduce production of a prostaglandin, putatively $\mathrm{PGE}_{2}$, that normally suppresses leukotriene synthesis via an EP receptor mechanism [2], possibly via phosphorylation of $\mathrm{LTC}_{4}$ synthase [6]. Increased cys-LT production is prominent in the acute bronchoconstriction that results, but it is not understood why NSAIDs trigger the acute surge in cys-LT levels only in AERD subjects.

In 1998, we described with our collaborators a marked overexpression of $\mathrm{LTC}_{4}$ synthase, the terminal enzyme for the cellular biosynthesis of the first of the cys-LTs, $\mathrm{LTC}_{4}$, in the bronchial mucosa of AERD patients [7]. LTC $_{4}$ synthase overexpression was also described in nasal polyps from aspirin-sensitive rhinitic patients [8]. A model for NSAID sensitivity was proposed in which enhanced expression of LTC $_{4}$ synthase in airway macrophages, mast cells, and eosinophils provides the enzymatic capacity for constitutive overproduction of cys-LTs in AERD [7,9]. Indeed, total 
numbers of LTC $_{4}$ synthase-positive cells in the bronchial mucosa correlate strikingly with increased cys-LT levels in BAL fluid in AERD subjects [7]. Overexpression of $\mathrm{LTC}_{4}$ synthase may also explain why only AERD subjects respond adversely to NSAID challenge, as suggested by the unique relationship between bronchial $\mathrm{LTC}_{4}$ synthase and airway hyperresponsiveness to aspirin challenge [7].

The view that $\mathrm{LTC}_{4}$ synthase overexpression is a central anomaly in AERD is supported by recent work in $\mathrm{LTC}_{4}$ synthase transgenic mice [10], although the potential mechanisms involved remain unclear. $\mathrm{LTC}_{4}$ synthase can be upregulated by cytokines, including interleukin (IL)-3 and IL-5 in maturing eosinophils [11] and IL-4 and IL-13 in human cord-blood mast cells [12], while TNF $\alpha$ downregulates $\mathrm{LTC}_{4}$ synthase in monocytes [13]. Immunoexpression of IL-5, but not IL-3 or GMCSF, is increased in AERD biopsies relative to aspirin-tolerant subjects [7], but there are no studies of IL-13 in AERD lung. Macrophages from resected human lung may represent a useful cellular model for AERD as they are primary cells that express both the $5-\mathrm{LO} / \mathrm{LTC}_{4}$ synthase and COX biosynthetic pathway enzymes, and also receptors for IL-13 that mediate increased expression of the CysLT receptor [14]. We hypothesised that culture of human lung macrophages with IL-13 would increase $\mathrm{LTC}_{4}$ synthase gene transcription and cys-LT synthesis compared to control macrophages. We also hypothesised that the NSAID, indomethacin, would trigger a further release of cys-LTs only in the IL-13-treated cells.

\section{Methods}

2.1. Materials. RNALater and the DNA Mastermix were purchased from Ambion (Warrington, UK). TaqMan Universal Master Mix, $\beta$-actin and LTC4S gene expression assays, and MicroAmp optical adhesive film were purchased from Applied Biosystems (Warrington, UK). The ImProm-II reverse transcription system was purchased from Promega (Southampton, UK). The cysteinyl-leukotriene enzyme immunoassay (EIA) kit was from Cayman Chemical Europe (Tallinn, Estonia). TRIzol was purchased from Invitrogen (Paisley, UK). Recombinant human IL-13 was purchased from PeproTech (London, UK). Calcium ionophore calcimycin (A23187), indomethacin, Trypan Blue solution $(0.4 \%)$, and dimethylsulphoxide (DMSO) were from Sigma Chemical Company (Poole, UK).

2.2. Isolation and Culture of Human Lung Macrophages. Samples of lung tissue (wet weight $1.8-35.2 \mathrm{~g}$ ) were collected from male and female patients undergoing bullectomy or lobectomy for lung cancer at the Southampton General Hospital, in accordance with ethical approval (08/HO502/32) from the Southampton and South-West Hampshire Research Ethics Committee. None had a history of asthma, but all were current or exsmokers. Tissue samples were dissected into $3 \mathrm{~mm}$ fragments and suspended in Dulbecco's phosphate-buffered saline (PBS) containing $0.1 \mathrm{M} \mathrm{NaCl}, 2.7 \mathrm{mM}$ $\mathrm{KCl}, 1.8 \mathrm{mM} \mathrm{KH}_{2} \mathrm{PO}_{4}$, and $10 \mathrm{mM} \mathrm{Na} \mathrm{PO}_{4}$ (pH 7.4). The suspension was centrifuged $\left(80 \times \mathrm{g}, 20^{\circ} \mathrm{C}\right.$ ) for $5 \mathrm{~min}$, the supernatant was discarded, and the pellet was resuspended in $30 \mathrm{~mL}$ of lysis buffer $\left(155 \mathrm{mM} \mathrm{NH}_{4} \mathrm{Cl}, 10 \mathrm{mM}\right.$ $\mathrm{KHCO}_{3}, 0.1 \mathrm{mM}$ EDTA; pH 7.4). After $5 \mathrm{~min}$ at room temperature, the suspension was filtered $(70 \mu \mathrm{m}$ filter $)$ and centrifuged $\left(80 \times \mathrm{g}, 20^{\circ} \mathrm{C}, 5 \mathrm{~min}\right)$ to remove erythrocyte fragments and other debris. The pellet was resuspended in RPMI medium supplemented with antibiotics (penicillin $55 \mathrm{U} / \mathrm{mL}$, streptomycin $5 \mathrm{mg} / \mathrm{mL}$, and gentamycin $10 \mathrm{mg} / \mathrm{mL}$ ). The resulting cell population was $>90 \%$ pure macrophages by morphology and had viability $>90 \%$ as determined by exclusion of Trypan Blue dye. Macrophage aliquots were cultured in RPMI $\left(0.5 \times 10^{6}\right.$ cells $\left./ \mathrm{mL}\right)$ at $37^{\circ} \mathrm{C}$ for $16 \mathrm{~h}$ overnight with or without IL-13 $(10 \mathrm{ng} / \mathrm{mL})$ in a $5 \% \mathrm{CO}_{2}$ humidified atmosphere.

For cys-LT assays, IL-13-treated and untreated cells were incubated for a further $30 \mathrm{~min}$ in fresh RPMI medium $(0.5 \times$ $10^{6}$ cells in $1 \mathrm{~mL}$ ) in a $37^{\circ} \mathrm{C}$ water bath with no addition (control), with indomethacin $(100 \mu \mathrm{M})$, with calcimycin (A23187, $1 \mu \mathrm{M}$ ), or with both indomethacin and A23187 at the same concentrations. Calcimycin (A23187) is a calcium ionophore that liberates arachidonic acid from membrane phospholipids and activates 5-LO to initiate leukotriene synthesis. Indomethacin is a classical NSAID which inhibits both COX-1 and COX-2 at the concentration used. These reagents were diluted from stock solutions in dimethylsulfoxide (DMSO) such that final DMSO concentration in the cell incubations was always $<0.2 \%$. At the end of the incubation, tubes were removed onto ice and centrifuged $\left(240 \times \mathrm{g}, 4^{\circ} \mathrm{C}\right)$ for 5 minutes to pellet the cells for RNA analyses. The supernatants were treated with two volumes of ethanol to precipitate protein, which was removed by centrifugation. Ethanolic supernatants were then evaporated to dryness in vacuo in a GyroVap rotary evaporator and stored at $-20^{\circ} \mathrm{C}$ before cys-LT immunoassays.

2.3. RT-qPCR Assay for LTC4S. For LTC4S gene transcription assays, aliquots $\left(10 \times 10^{6}\right.$ cells) of IL-13-treated and untreated cell pellets were mixed with $0.5 \mathrm{~mL}$ RNALater and kept at $4^{\circ} \mathrm{C}$ for $24 \mathrm{~h}$, then stored at $-20^{\circ} \mathrm{C}$ before RNA extraction and reverse-transcriptase quantitative polymerase chain reaction (RT-qPCR) assays for LTC4S and beta-actin mRNAs. Macrophages were thawed, vortexed, and transferred into RNA-free Eppendorf tubes. PBS $(1 \mathrm{~mL})$ was added, and Eppendorfs were vortexed and centrifuged $\left(2800 \times \mathrm{g}, 20^{\circ} \mathrm{C}\right)$ for $5 \mathrm{~min}$ to decrease the viscosity of the RNALater and allow the macrophages to form a pellet. RNALater was then removed and the RNA extracted using TRIzol (Invitrogen, Paisley, UK) by the manufacturer's protocol. Residual genomic DNA was digested using Ambion DNA-free (Applied Biosystems, Warrington, UK). For each RNA sample, the A260/A280 ratio measured by spectrophotometry (Nanodrop ND1000, ThermoFisher Hemel Hempstead, UK) was $>1.8$, indicating an adequate level of purity, and RNA was stored at $-80^{\circ} \mathrm{C}$. To generate cDNA, $1 \mu \mathrm{g}$ of RNA was reverse transcribed (Improm-II RT system, Promega, Southampton, UK) using random hexamer primers and stored at $-20^{\circ} \mathrm{C}$.

RT-qPCR was performed on the Lightcycler 480 (Roche Diagnostics, UK) in 384-well reaction plates using $\sim 100 \mathrm{ng}$ of template cDNA in quadruplicate $20 \mu \mathrm{L}$ reactions using 
TaqMan gene expression assays for LTC4S (Hs00168529_m1) with ACTB (beta-actin, Hs99999903_m1) as a reference gene, both using FAM-labelled hydrolysis probes and TaqMan universal mastermix II for 40 cycles, as in the manufacturer's protocol (Applied Biosystems). Gene expression relative to ACTB was calculated using the $2^{-\Delta \Delta C q}$ method. Paired statistical comparison between IL-13-treated and untreated cells from $n=12$ donors was performed by Wilcoxon signed rank test for nonparametric data.

2.4. Cysteinyl-Leukotriene Immunoassays. Evaporated supernatants from $30 \mathrm{~min}$ incubations of IL-13-treated and untreated macrophages with and without indomethacin and calcimycin were resuspended in appropriate volumes of PBS buffer and aliquots taken in duplicate for EIA quantification of released cys-LTs. The total cys-LT EIA kits (Cayman Europe) use a monoclonal primary antibody with $100 \%$ specificity for $\mathrm{LTC}_{4}$ and $\mathrm{LTD}_{4}$ and $79 \%$ specificity for $\mathrm{LTE}_{4}$. Cross-reactivity to $\mathrm{LTB}_{4}$, various HETEs, and arachidonate is less than $4 \%$ and the assay has high sensitivity $(34 \mathrm{pg} / \mathrm{mL})$ for cys-LTs. The assay is based on competition with a standard LTC $_{4}$-acetylcholinesterace tracer with Ellman's reagent as substrate. Cys-LTs were assayed in duplicate, and concentrations are expressed as nanograms of $\mathrm{LTC}_{4}$ released per million viable macrophages. Data are presented as mean \pm SEM for $n=8$ tissue donors, and comparisons between mean values were made by two-tailed paired Student's $t$-tests, with $P<0.05$ considered significant.

\section{Results}

For LTC4S gene transcription assays, human lung macrophages from 12 donors ( 9 male, three female; mean age 64 years, range 49-78 years) were cultured overnight for 16 hours with or without IL-13 (10 ng/mL). LTC4S mRNA expression in each cell sample was detected in quadruplicate using RT-qPCR, with $\beta$-actin as the housekeeping gene. The mean expression of LTC4S mRNA at 16 hours was not significantly different in IL-13-treated macrophages compared to their untreated cells (mean log $\Delta \Delta$ Cq value $=0.49, P=0.33$, $n=12$ ) (Figure 1). The comparison remained nonsignificant when the single outlying value, caused by an anomalously low control $(\beta$-actin) value in the untreated cells from one donor, which was not apparent in the IL-13-treated cells from the same donor, was excluded from the analysis.

Following 16-hour cultures with or without IL-13, macrophages from representative donors ( 8 males, mean age 67 years, range 56-76) underwent 30-minute incubations for detection of total cys-LT release (Figure 2). IL-13 pretreatment significantly increased spontaneous cys-LT release from $544 \pm 215 \mathrm{pg} / \mathrm{million}$ cells to $825 \pm 292 \mathrm{pg} /$ million cells $(P=0.02)$, a mean increase of $52 \pm 17 \%$. Incubation with indomethacin $(100 \mu \mathrm{M})$ did not significantly change cys-LT release when compared with spontaneous release in either IL-13-treated or untreated cells $(P>0.05)$.

As expected, the calcium ionophore A23187 (calcimycin, $1 \mu \mathrm{M})$ boosted the mean release of total cys-LTs by about 10-fold compared with spontaneous release. Mean

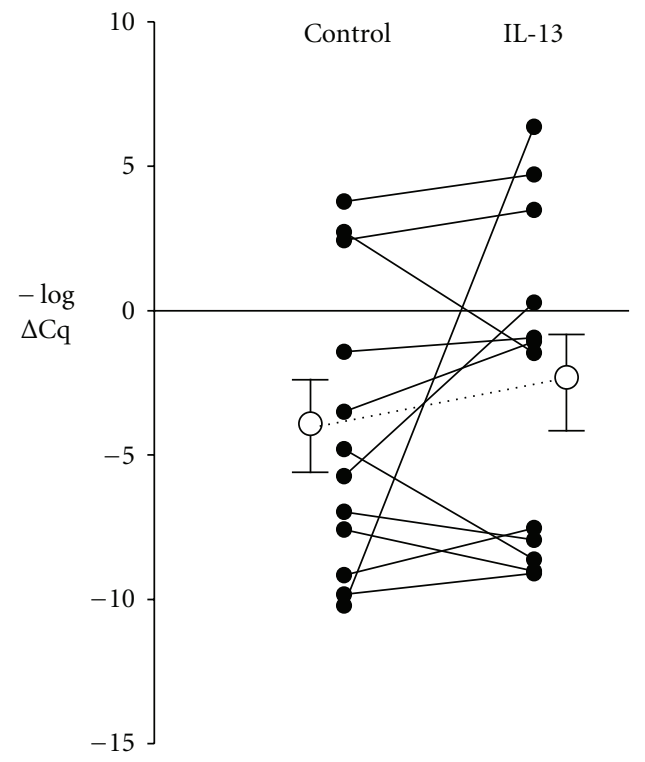

FIGURE 1: RT-qPCR assay data for LTC4S mRNA in macrophages from 12 lung tissue donors after 16 hours of culture in the presence and absence of $10 \mathrm{ng} / \mathrm{mL}$ IL-13. Values are normalised to the housekeeping gene ( $\beta$-actin), with $\Delta \mathrm{Cq}$ values representing the number of doubling cycles taken to reach the threshold, and plotted on an inverted logarithmic $y$-axis (as $-\Delta \mathrm{Cq}$ ) so that an increase in LTC4S mRNA is shown as a higher value on the axis. The mean log change in $-\triangle \mathrm{Cq}$ value was 0.49 , representing no significant change in LTC4S mRNA with IL-13 culture $(P=0.3)$.

release of total cys-LTs after 30 min of A23187 stimulation was significantly greater in IL-13-treated cells $(7770 \pm$ $630 \mathrm{pg} /$ million cells) than in cells not treated with IL-13 $(5480 \pm 670 \mathrm{pg} / \mathrm{million}$ cells $)(P=0.005)$, a mean increase of $42 \pm 10 \%$ (Figure 2). Coincubation of indomethacin $(100 \mu \mathrm{M})$ and $\mathrm{A} 23187(1 \mu \mathrm{M})$ however did not show different values for cys-LT release compared with A23187 alone in either IL-13 pretreated or untreated cells.

\section{Discussion}

Interleukin (IL)-13 is a Th2 cytokine with well-established roles in promoting airway responsiveness, mucus secretion, and chemokine production in the allergic lung, acting principally via a receptor shared with IL-4 and leading to phosphorylation of the transcription factor STAT6 [15]. IL4 can powerfully upregulate $\mathrm{LTC}_{4}$ synthase expression and activity in human cord-blood mast cells [12], while IL-13 can upregulate the principal receptor for cysteinyl-leukotrienes, CysLT1R, on human airway smooth muscle cells [16] and on macrophages [14]. This suggested that increased IL-4/IL-13 activity may be responsible for upregulating tissue expression of LTC $_{4}$ synthase, as observed in the upper and lower airways in AERD patients $[7,8]$, and for enhancing responsiveness to cys-LTs by increasing the expression of $\mathrm{CysLT}_{1}$ receptors, as described in AERD nasal biopsies [17]. 
Control

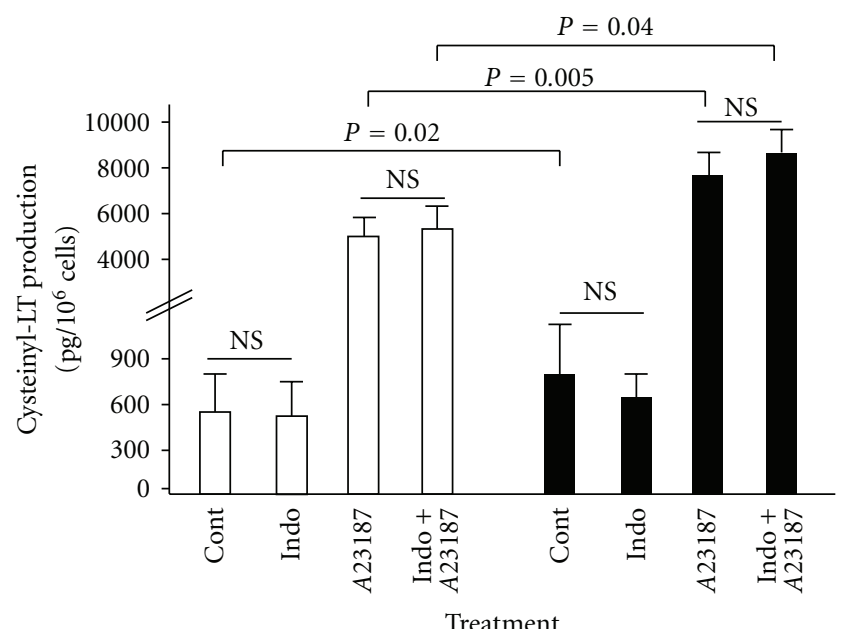

Figure 2: Enzyme immunoassay data on release of total cysteinylleukotrienes (cys-LT, pg/million cells) by macrophages from eight lung tissue donors after culture for 16 hours in the absence or presence of IL-13 (10 ng/mL). Macrophages were then washed and resuspended in fresh medium for a $30 \mathrm{~min}$ incubation with no further addition (Cont), with the NSAID indomethacin (Indo, $100 \mu \mathrm{M})$, with the calcium ionophore calcimycin (A23187, $1 \mu \mathrm{M}$ ), or with both indomethacin and calcimycin (Indo + A23187). Pretreatment with IL-13 significantly increased spontaneous cys-LT release $(P=0.02)$ and that induced by calcimycin $(P=0.005)$, but neither was affected by indomethacin in either IL-13 treated or untreated cells.

This study therefore explored whether IL-13 can upregulate $\mathrm{LTC}_{4}$ synthase transcriptional expression in macrophages isolated from resected human lung and whether it leads to a higher release of cys-LTs, either spontaneously or in response to a calcium ionophore, compared with macrophages not cultured with IL-13. Taqman gene expression assays failed to show significant changes in LTC4S mRNA, standardised to the beta-actin housekeeping gene (ACTB), in IL-13 cultures of macrophages from twelve lung tissue donors (Figure 1). Increases in LTC4S mRNA are detectable after six hours of IL-4 treatment in human mast cells derived from cord blood mononuclear cells, and maximal at 24 to 120 hours [12], suggesting that the 16-hour culture with IL-13 employed in our experiments was reasonable. IL-13 may be less potent on myeloid cells than IL-4, and our cells were mature lung macrophages from mainly elderly subjects undergoing lobectomy or bullectomy; these cells may not be as responsive to IL-13 or other stimuli as cord-blood-derived mononuclear cells from healthy neonates.

Despite the lack of effect on LTC4S transcription, culture of lung macrophages with IL-13 did cause significant increases in cys-LT release, an effect that was apparent both on the low levels of spontaneous cys-LT production in unstimulated cells and on the tenfold higher levels of cys-LT release measured in cells stimulated with calcimycin A23187 (Figure 2). Calcimycin acts as a receptor-independent trigger of arachidonate release from membrane phospholipids; a high turnover of substrate through the 5 -LO/LTC 4 synthase pathway was intended to simulate rate-limiting conditions, such that an increase in $\mathrm{LTC}_{4}$ synthase enzyme expression induced by IL-13 could be revealed by a raised ceiling of cysLT synthesis. In the event, the lack of upregulation of LTC4S mRNA suggests either a nontranscriptional effect of IL-13 or an action on other components of the pathway, possibly on 5-LO activating protein (FLAP), which is inducible by cytokines and increases markedly during human alveolar macrophage maturation [18]. The increases in cys-LT release seen in the IL-13-cultured macrophages were relatively modest (42-52\%), but suggest that IL-13 could contribute to increased cys-LT releasability in macrophages in the allergic asthmatic or AERD lung.

NSAIDs such as indomethacin are proposed to cause acute AERD reactions by shunting of arachidonate from the inhibited COX pathway to the 5 -LO/LTC 4 synthase pathway or by suppressing synthesis of an inhibitory prostanoid such as $\mathrm{PGE}_{2}$, thus enhancing cys-LT production [6]. Although isolated anomalies in COX isozyme expression, prostanoid synthesis, and EP receptor signalling have been described in AERD cells and tissues $[19,20]$, a coherent picture of a systemic prostanoid defect in AERD has yet to emerge [2]. Human alveolar macrophages constitutively express COX-1 and synthesise $\mathrm{PGE}_{2}$ [21]. We postulated that endogenous COX pathways in human lung macrophages may therefore provide an adequate target for NSAID action, resulting in enhanced cys-LT release if the 5 - $\mathrm{LO} \mathrm{LTC}_{4}$ synthase pathway has previously been induced by IL-13. No effect of indomethacin was observed however on either spontaneous or A23187stimulated cys-LT release in either IL-13-treated or untreated cells (Figure 2). In the absence of an effect of IL-13 on LTC4S mRNA levels, it is not possible to reject our hypothesis that LTC $_{4}$ synthase overexpression in a single cell type could provide a simple cellular model of the key functional changes within the AERD lung. In vivo, intercellular interactions may be required, possibly with $\mathrm{PGE}_{2}$ derived from airway epithelial cells [22] or it may depend on the recruitment of new populations of LTC $_{4}$-synthase-expressing cells, such as eosinophils. It is nevertheless intriguing that human mast cells derived in culture from the blood mononuclear cells of AERD subjects show an intrinsically raised capacity for cys-LT synthesis and that this is suppressed by $\mathrm{PGE}_{2}$ [23], suggesting that the AERD paradigm can be detected at the level of a single cell type and that it persists in prolonged cell culture. Further comparative studies are required in primary lung cell populations from normal and AERD subjects.

The key features of AERD have recently been replicated in ovalbumin-sensitised $\mathrm{LTC}_{4}$ synthase transgenic mice (LTC4S-Tg), including its overexpression in airway macrophages and other leukocytes, leading to increased cys-LT synthesis both before and after NSAID challenge, accompanied by dramatically increased Th2 cytokines, including IL-13 [10]. This model suggests that primary dysregulation of LTC $_{4}$ synthase in resident lung cells including macrophages may initiate overproduction of cys-LTs in patients with AERD. The cys-LTS may then promote the secondary synthesis of IL-4, IL-5, and IL-13 from lymphocytes [10] and eosinophils [24], leading to myocyte CysLT1R expression [16], 
suppression of epithelial $\mathrm{PGE}_{2}$ synthesis and EP2 expression [22], and further induction of $\mathrm{LTC}_{4}$ synthase [11]. While the LTC4S - 444A/C promoter polymorphism [25] has been discounted as an aetiological factor in most AERD populations [26], other genetic, immunological, and microbial factors that could directly dysregulate $\mathrm{LTC}_{4}$ synthase in human lung cells merit further investigation.

\section{Acknowledgments}

S. E. Jackson was supported by a Wolfson Foundation intercalated BSc bursary. The authors thank the Asthma, Allergy \& Inflammation Research (AAIR) Charity (http://www.aaircharity.org/) for funding to develop the RT-qPCR assays used in this study.

\section{References}

[1] D. D. Stevenson, "Aspirin sensitivity and desensitization for asthma and sinusitis," Current Allergy and Asthma Reports, vol. 9, no. 2, pp. 155-163, 2009.

[2] S. P. Farooque and T. H. Lee, "Aspirin-sensitive respiratory disease," Annual Review of Physiology, vol. 71, pp. 465-487, 2009.

[3] P. Gyllfors, G. Bochenek, J. Overholt et al., "Biochemical and clinical evidence that aspirin-intolerant asthmatic subjects tolerate the cyclooxygenase 2-selective analgetic drug celecoxib," Journal of Allergy and Clinical Immunology, vol. 111, no. 5, pp. 1116-1121, 2003.

[4] M. Peters-Golden and W. R. Henderson, "Mechanisms of disease: leukotrienes," New England Journal of Medicine, vol. 357, no. 18, pp. 1841-1854, 2007.

[5] P. M. O'Byrne, G. M. Gauvreau, and D. M. Murphy, "Efficacy of leukotriene receptor antagonists and synthesis inhibitors in asthma," Journal of Allergy and Clinical Immunology, vol. 124, no. 3, pp. 397-403, 2009.

[6] J. Esser, U. Gehrmann, M. D. Salvado et al., "Zymosan suppresses leukotriene $\mathrm{C}_{4}$ synthase activity in differentiating monocytes: antagonism by aspirin and protein kinase inhibitors," FASEB Journal, vol. 25, no. 4, pp. 1417-1427, 2011.

[7] A. S. Cowburn, K. Sladek, J. Soja et al., "Overexpression of leukotriene $\mathrm{C}_{4}$ synthase in bronchial biopsies from patients with aspirin-intolerant asthma," Journal of Clinical Investigation, vol. 101, no. 4, pp. 834-846, 1998.

[8] J. Adamjee, H. J. Suh, H. S. Park et al., "Expression of 5lipoxygenase and cyclooxygenase pathway enzymes in nasal polyps of patients with aspirin-intolerant asthma," Journal of Pathology, vol. 209, no. 3, pp. 392-399, 2006.

[9] M. Sanak and A. P. Sampson, "Biosynthesis of cysteinyl-leucotrienes in aspirin-intolerant asthma," Clinical and Experimental Allergy, vol. 29, no. 3, pp. 306-313, 1999.

[10] H. Hirata, M. Arima, Y. Fukushima et al., "Over-expression of the $\mathrm{LTC}_{4}$ synthase gene in mice reproduces human aspirininduced asthma," Clinical and Experimental Allergy, vol. 41, no. 8, pp. 1133-1142, 2011.

[11] J. A. Boyce, B. K. Lam, J. F. Penrose et al., "Expression of $\mathrm{LTC}_{4}$ synthase during the development of eosinophils in vitro from cord blood progenitors," Blood, vol. 88, no. 11, pp. 4338-4347, 1996.

[12] F. H. Hsieh, B. K. Lam, J. F. Penrose, K. F. Austen, and J. A. Boyce, "T helper cell type 2 cytokines coordinately regulate immunoglobulin E-dependent cysteinyl leukotriene production by human cord blood-derived mast cells: profound induction of leukotriene $\mathrm{C}_{4}$ synthase expression by interleukin 4," Journal of Experimental Medicine, vol. 193, no. 1, pp. 123$133,2001$.

[13] K. J. Serio, C. Luo, L. Luo, and J. T. Mao, "TNF- $\alpha$ downregulates the leukotriene $\mathrm{C}_{4}$ synthase gene in mononuclear phagocytes," American Journal of Physiology, vol. 292, no. 1, pp. L215-L222, 2007.

[14] M. Thivierge, J. Staňková, and M. Rola-Pleszczynski, "IL-13 and IL-4 up-regulate cysteinyl leukotriene 1 receptor expression in human monocytes and macrophages," Journal of Immunology, vol. 167, no. 5, pp. 2855-2860, 2001.

[15] J. W. Steinke, J. A. Culp, E. Kropf, and L. Borish, "Modulation by aspirin of nuclear phospho-signal transducer and activator of transcription 6 expression: possible role in therapeutic benefit associated with aspirin desensitization," Journal of Allergy and Clinical Immunology, vol. 124, no. 4, pp. 724-730, 2009.

[16] K. Espinosa, Y. Bossé, J. Stankova, and M. Rola-Pleszczynski, "CysLT1 receptor upregulation by TGF- $\beta$ and IL-13 is associated with bronchial smooth muscle cell proliferation in response to $\mathrm{LTD}_{4}$," Journal of Allergy and Clinical Immunology, vol. 111, no. 5, pp. 1032-1040, 2003.

[17] A. R. Sousa, A. Parikh, G. Scadding, C. J. Corrigan, and T. H. Lee, "Leukotriene-receptor expression on nasal mucosal inflammatory cells in aspirin-sensitive rhinosinusitis," New England Journal of Medicine, vol. 347, no. 19, pp. 1493-1499, 2002.

[18] M. J. Coffey, S. E. Wilcoxen, and M. Peters-Golden, "Increases in 5-lipoxygenase activating protein expression account for enhanced capacity for 5-lipoxygenase metabolism that accompanies differentiation of peripheral blood monocytes into alveolar macrophages," American Journal of Respiratory Cell and Molecular Biology, vol. 11, no. 2, pp. 153-158, 1994.

[19] M. L. Kowalski, R. Pawliczak, J. Wozniak et al., "Differential metabolism of arachidonic acid in nasal polyp epithelial cells cultured from aspirin-sensitive and aspirin-tolerant patients," American Journal of Respiratory and Critical Care Medicine, vol. 161, no. 2 I, pp. 391-398, 2000.

[20] C. A. Pérez-Novo, J. B. Watelet, C. Claeys, P. Van Cauwenberge, and C. Bachert, "Prostaglandin, leukotriene, and lipoxin balance in chronic rhinosinusitis with and without nasal polyposis," Journal of Allergy and Clinical Immunology, vol. 115, no. 6, pp. 1189-1196, 2005.

[21] T. Endo, F. Ogushi, T. Kawano, and S. Sone, "Comparison of the regulations by Th2-type cytokines of the arachidonicacid metabolic pathway in human alveolar macrophages and monocytes," American Journal of Respiratory Cell and Molecular Biology, vol. 19, no. 2, pp. 300-307, 1998.

[22] J. Trudeau, H. Hu, K. Chibana, H. W. Chu, J. Y. Westcott, and S. E. Wenzel, "Selective downregulation of prostaglandin E2related pathways by the TH2 cytokine IL-13," Journal of Allergy and Clinical Immunology, vol. 117, no. 6, pp. 1446-1454, 2006.

[23] X. S. Wang, A. Y. Y. Wu, P. S. Leung, and H. Y. A. Lau, "PGE2 suppresses excessive anti-IgE induced cysteinyl leucotrienes production in mast cells of patients with aspirin exacerbated respiratory disease," Allergy, vol. 62, no. 6, pp. 620-627, 2007.

[24] C. Bandeira-Melo, J. C. Hall, J. F. Penrose, and P. F. Weller, "Cysteinyl leukotrienes induce IL-4 release from cord bloodderived human eosinophils," Journal of Allergy and Clinical Immunology, vol. 109, no. 6, pp. 975-979, 2002. 
[25] M. Sanak, H. U. Simon, and A. Szczeklik, "Leukotriene $C_{4}$ synthase promoter polymorphism and risk of aspirin-induced asthma," The Lancet, vol. 350, no. 9091, pp. 1599-1600, 1997.

[26] N. P. Duroudier, A. S. Tulah, and I. Sayers, "Leukotriene pathway genetics and pharmacogenetics in allergy," Allergy, vol. 64, no. 6, pp. 823-839, 2009. 


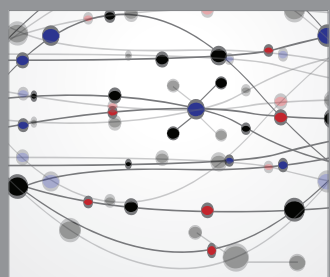

The Scientific World Journal
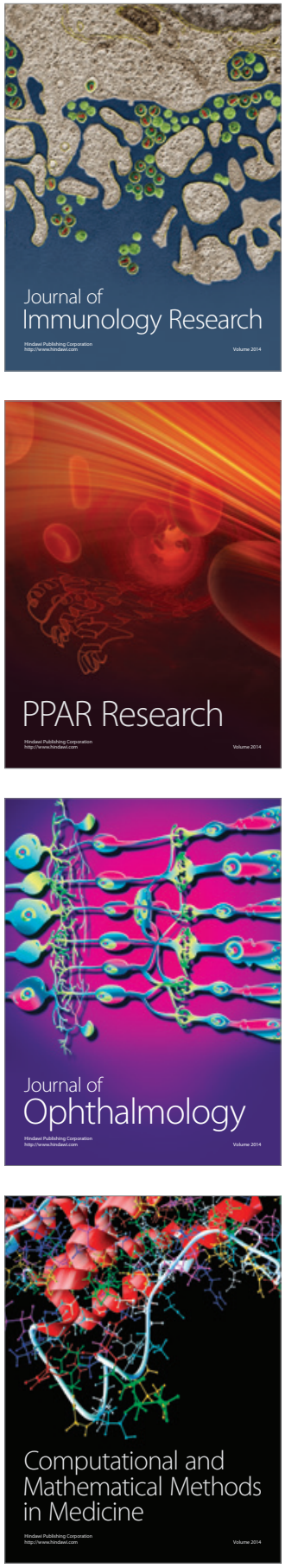

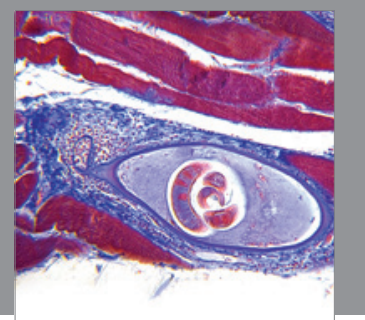

Gastroenterology

Research and Practice
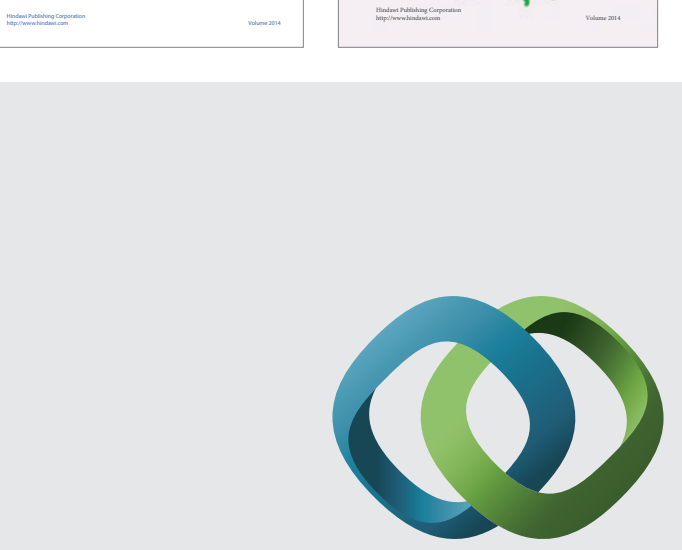

\section{Hindawi}

Submit your manuscripts at

http://www.hindawi.com
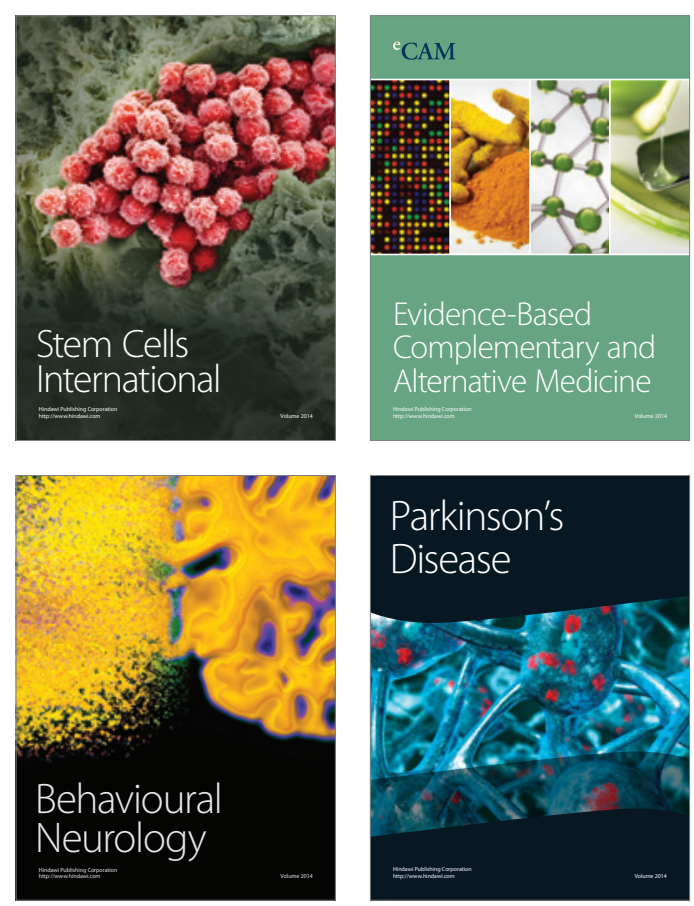

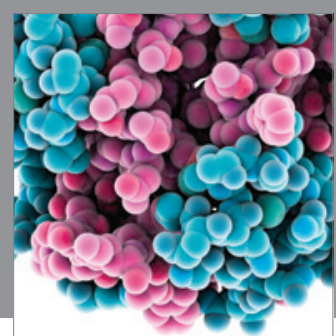

Journal of
Diabetes Research

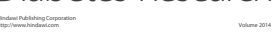

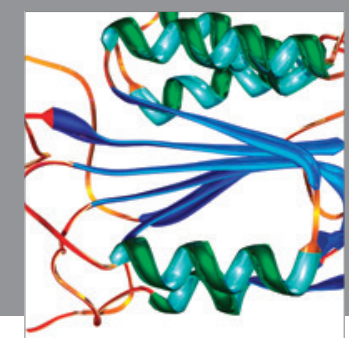

Disease Markers
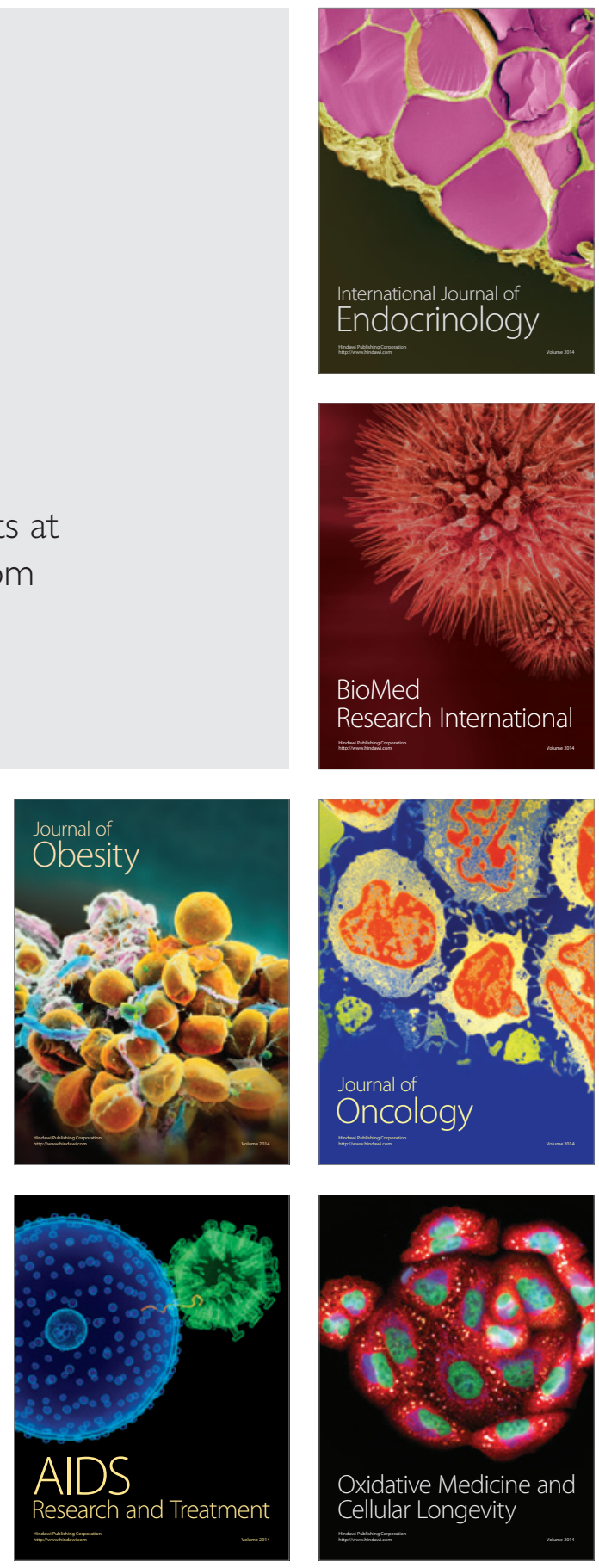